\title{
How does tautomerization affect the excited-state dynamics of an amino acid-derivatized corrole?
}

\author{
John A. Clark ${ }^{1}$ - Rafał Orłowski ${ }^{2}$ James B. Derr ${ }^{3}$ - Eli M. Espinoza ${ }^{4,6} \cdot$ Daniel T. Gryko $^{2}$ (i) $\cdot$ Valentine I. Vullev ${ }^{1,3,4,5}$ (D)
}

Received: 24 August 2020 / Accepted: 22 January 2021 / Published online: 12 March 2021

(c) The Author(s) 2021

\begin{abstract}
In the first two decades of the XXI century, corroles have emerged as an important class of porphyrinoids for photonics and biomedical photonics. In comparison with porphyrins, corroles have lower molecular symmetry and higher electron density, which leads to uniquely complementary properties. In macrocycles of free-base corroles, for example, three protons are distributed among four pyrrole nitrogens. It results in distinct tautomers that have different thermodynamic energies. Herein, we focus on the excited-state dynamics of a corrole modified with L-phenylalanine. The tautomerization in the singlet-excited state occurs in the timescales of about 10-100 picoseconds and exhibits substantial kinetic isotope effects. It, however, does not discernably affect nanosecond deactivation of the photoexcited corrole and its basic photophysics. Nevertheless, this excited-state tautomerization dynamics can strongly affect photoinduced processes with comparable or shorter timescales, considering the 100-meV energy differences between the tautomers in the excited state. The effects on the kinetics of charge transfer and energy transfer, initiated prior to reaching the equilibrium thermalization of the excited-state tautomer population, can be indeed substantial. Such considerations are crucially important in the design of systems for artificial photosynthesis and other forms of energy conversion and charge transduction.
\end{abstract}

Keywords Porphyrinoids · Corroles · Tautomers · Hydrogen bonding $\cdot$ Kinetic isotope effect $\cdot$ Transient-absorption spectroscopy

\section{Introduction}

JohnA. Clark and Rafał Orłowski have equal contributions.

Daniel T. Gryko

dtgryko@icho.edu.pl

$\triangle$ Valentine I. Vullev

vullev@ucr.edu

1 Department of Bioengineering, University of California, Riverside, CA 92521, USA

2 Institute of Organic Chemistry, Polish Academy of Sciences, Kasprzaka 44/52, 01-224 Warsaw, Poland

3 Department of Biochemistry, University of California, Riverside, CA 92521, USA

4 Department of Chemistry, University of California, Riverside, CA 92521, USA

5 Materials Science and Engineering Program, University of California, Riverside, CA 92521, USA

6 Present Address: College of Bioengineering, University of California, Berkeley, CA 94720, USA
This article describes the excited-state dynamics and the optical properties of a free-base (FB) corrole modified with L-phenylalanine, $\operatorname{Cor}\left(\mathbf{H}_{3}\right)$-Phe (Fig. 1). Deuteration of this conjugate does not noticeably affect its optical properties, such as absorption and emission spectra, as well as the excited-state lifetime. Picosecond transitions ascribed to excited-state tautomerization, on the other hand, manifest substantial kinetic isotope effects. While the tautomerization timescales are considerably faster than the deactivation to the ground state, they can be comparable to charge-transfer and energy-transfer reactions important for the design of systems for artificial photosynthesis.

As important as the discovery of corroles was in the 1960s (Johnson and Price 1960a, b; Johnson and Kay $1961,1964,1965)$, it was four decades later when the first reports of the one-pot syntheses of such macrocycles drew considerable attention to these chromophores by making them readily accessible (Gryko and Jadach 2001; Gross et al. 1999; Paolesse et al. 2001). Similar to 

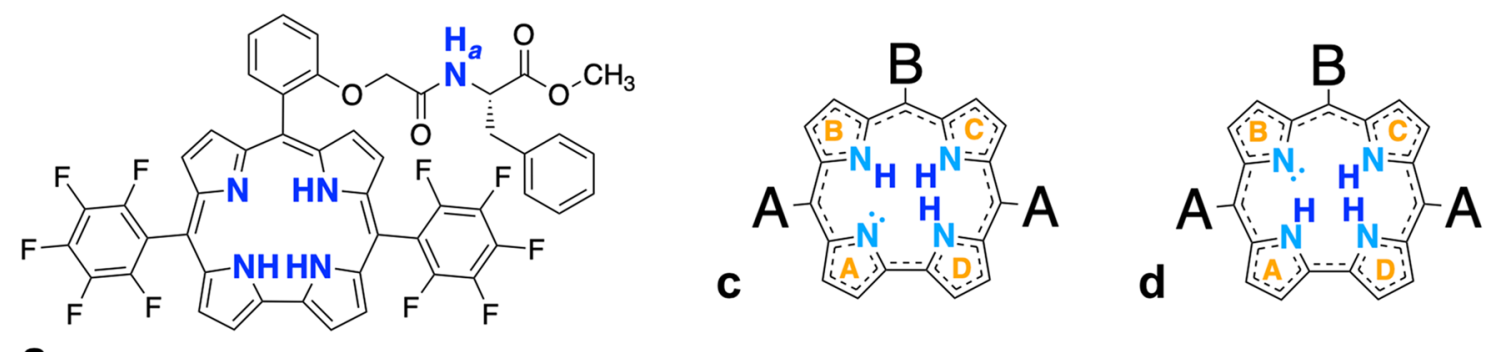

a
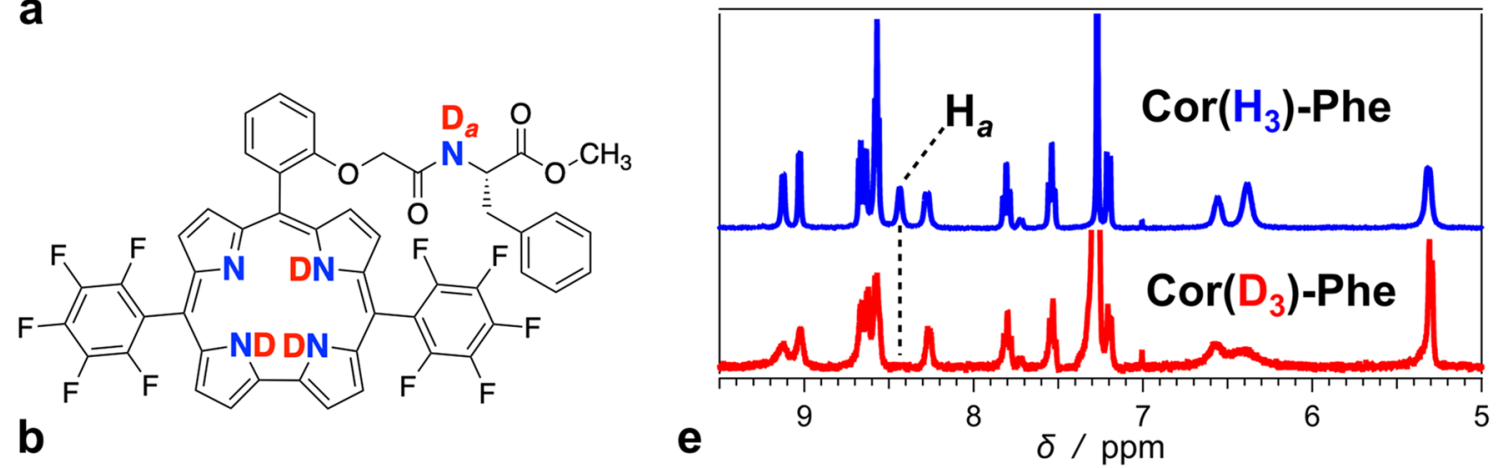

Fig. 1 Structures of a $\operatorname{Cor}\left(\mathbf{H}_{3}\right)$-Phe, b $\operatorname{Cor}\left(\mathbf{D}_{3}\right)$-Phe, $\mathbf{c}$ tautomer 1 (T1), and $\mathbf{d}$ tautomer 2 (T2) along with $\mathbf{e}$ the aromatic region of the ${ }^{1} \mathrm{H}$ NMR spectra (for $\mathrm{CDCl}_{3}$ ) of $\operatorname{Cor}\left(\mathbf{H}_{3}\right)$-Phe and $\operatorname{Cor}\left(\mathbf{D}_{3}\right)$-Phe (three washes of a $\operatorname{Cor}\left(\mathbf{H}_{3}\right)$-Phe chloroform solution with $\mathrm{D}_{2} \mathrm{O}$ yield $\mathbf{C o r}\left(\mathbf{D}_{3}\right)$-Phe, as the replacement of the amide proton, $\mathrm{H}_{a}$, indicates)

porphyrins, corroles are tetrapyrroles with one less carbon in the macrocycle, resulting in electron-rich chromophores with properties that are complementary to those of other porphyrinoids (Gryko 2002; Orlowski et al. 2017a; Aviv-Harel and Gross 2009; Ghosh 2017; Rabinovich et al. 2011; Pomarico et al. 2018; Einrem et al. 2016). The importance of corroles for solar energy conversion, photocatalysis, photodynamic therapy and other areas of photonics is well recognized (Dogutan et al. 2011; Mahammed and Gross 2006; Agadjanian et al. 2009; Flamigni et al. 2008; Teo et al. 2017).

In addition to increasing the electron density, the contraction of the macrocycle lowers the molecular symmetry. While many porphyrins belong to $D_{4 h}$ and $D_{2 h}$ point groups, the symmetry of planar corroles cannot exceed $C_{2 v}$. Furthermore, the sterics and the tension in such contracted macrocycles force the pyrrole rings in the FB corroles out of plane leading to $C_{s}$ and even $C_{1}$ symmetry. Such displacement of the pyrrole $\mathrm{N}-\mathrm{H}$ groups out of the macrocycle plane of the FB corroles drastically increases their acidity and propensity for hydrogen bonding (Szymanski et al. 2014). Even moderately polar solvents with weak basicity can deprotonate these FB porphyrinoids (Kruk et al. 2012).

The non-planar structure of FB corroles, exposing the pyrrole nitrogens to the media, enhances not only their acidity, but also their basicity. The $\mathrm{p} K_{a}$ values for nonprotonated corroles, i.e., $\operatorname{Cor}\left(\mathrm{H}_{3}\right)$, range between 4 and 7 , and monoprotonated ones, i.e., $\operatorname{Cor}\left(\mathrm{H}_{4}\right)^{+}$, exhibit $\mathrm{p} K_{a}$ in the range of 2-3 for aqueous media (Mahammed et al. 2003; Shen et al. 2007). They are quite smaller than the $\mathrm{p} K_{a}$ values for FB porphyrins, requiring strong acids to protonate them $\left(\mathrm{p} K_{a} \sim 4\right)$ and even stronger bases to deprotonate them $\left(\mathrm{p} K_{a}>30\right)$ in aqueous/organic media (Jimenez et al. 1991).

That is, the macrocycle arrangements push the protonated, rather than the deprotonated, pyrrole nitrogens out of plane improving their accessibility. In fact, the basicity of FB corroles and porphyrins is similar, with their monoprotonated forms exhibiting similar $\mathrm{p} K_{a}$ values ranging between about 5 and 6 for aqueous media.

In their macrocycles, non-ionized FB corroles contain three protons distributed over four pyrrole nitrogens. Because of the molecular asymmetry, the four pyrroles are not equivalent. This feature results in discernable tautomers of FB corroles, as determined by the position of the deprotonated pyrrole nitrogen. FB corroles with $C_{s}$ symmetry exist in the form of two tautomers. In the first tautomer, T1, the deprotonated nitrogen is on one of the two directly linked pyrroles, i.e., ring A or D (Fig. 1c). In the second tautomer, $\mathrm{T} 2$, one of the two pyrroles, linked to methines on both sides, i.e., ring $\mathrm{B}$ or $\mathrm{C}$, is deprotonated (Fig. 1d). Lowering the molecular symmetry to $C_{1}$ increases the number of possible tautomers of FB corroles.

In the ground state, the energy difference between $\mathrm{T} 1$ and $\mathrm{T} 2$ is small. It does not exceed $5 \mathrm{meV}$ and $\mathrm{T} 2$ is slightly favored over T1 (Chandler et al. 2009; Kruk et al. 2012; Ding et al. 2005). This small energy difference results almost 
equimolar populations of the two tautomers at room temperature. In the excited states, on the other hand, the energy level of the tautomer with lesser crowding of the protons, i.e., T1, is about $100 \mathrm{meV}$ below that of T2 (Szymanski et al. 2014; Kruk et al. 2012; Ding et al. 2005). These energy differences suggest that $\mathrm{T} 1$ defines the photophysics of FB corroles, assuming sufficiently fast tautomerization. Therefore, while the absorption spectra reveal transitions involving $\mathrm{T} 1$ and $\mathrm{T} 2$, the fluorescence spectra at room temperature (for non-polar liquid media) show solely the emission from $\mathrm{T} 1$ that is bathochromically shifted in comparison to where T2 emits (Szymanski et al. 2014; Kruk et al. 2012; Ding et al. 2005).

The differences in the electronic properties between the tautomers result not only in different acidities and photophysical characteristics, but also in different propensities of the FB corroles to act as electron and energy donors and acceptors. Photoinduced processes that are slower than the tautomerization rates should originate from the lowest excited state of the energetically preferred structure. Conversely, the starting points of photoinduced reactions occurring in timescales considerably shorter than the time constants of tautomerization, i.e., $\tau=k^{-1} \ll \tau_{\text {taut }}$, are representative of the ground-state population distribution of the different structures. This feature warrants the need for understanding the tautomerization dynamics of FB corrles in order to broaden and optimize their utility for photonics and biophotonics.

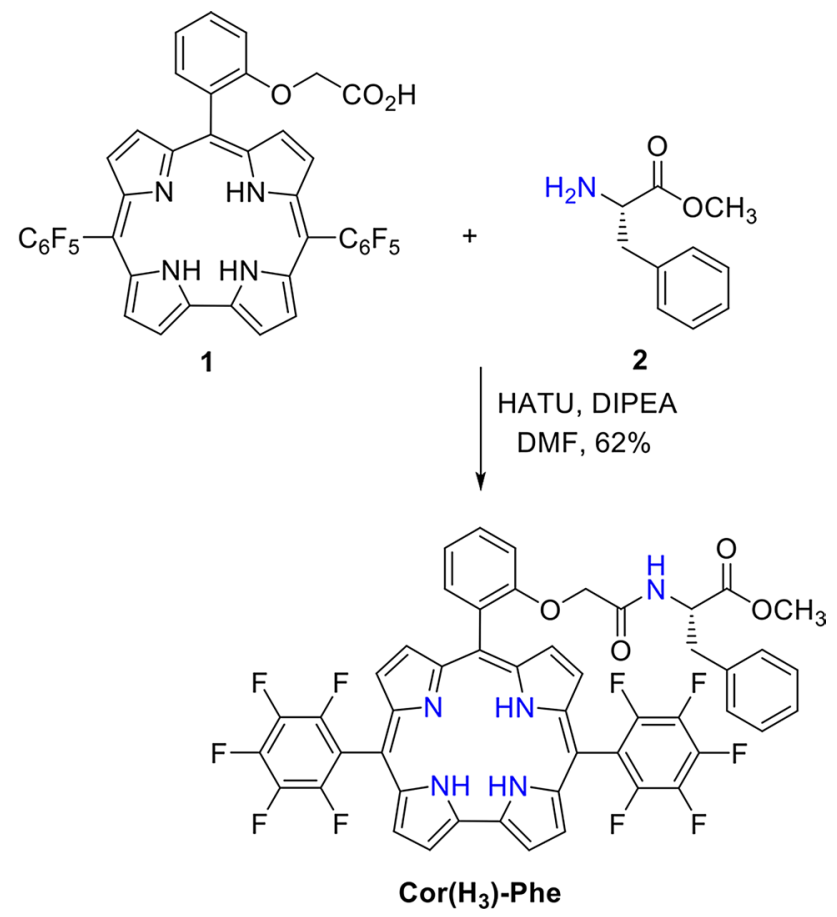

Scheme 1 Synthesis of $\operatorname{Cor}\left(\mathbf{H}_{3}\right)$-Phe
Herein, we focus on the excited-state dynamics of an FB trans- $\mathrm{A}_{2} \mathrm{~B}$-corrole linked with a phenylalanine, $\operatorname{Cor}\left(\mathbf{H}_{3}\right)$ Phe (Fig. 1a). Transient-absorption (TA) spectroscopy reveals transitions in the 10 to 100 ps timescales, which are consistent with excited-state tautomerization and exhibit hydrogen kinetic isotope effects ranging between 2.6 and 3.9. These findings indicate that the dynamics of tautomerization of FB corroles does not affect nanosecond and slower processes, i.e., they originate from equilibrium excited-state populations of tautomers. The excited-state tautomerization dynamics, however, can be deterministic for femtosecond and picosecond reactions, such as charge injection from photoexcited FB corroles into semiconductors, essential for light harvesting, energy conversion, and overall for artificial photosynthesis.

\section{Results and discussion}

\section{Corrole design}

Corroles, containing $O$-linked glycolamides to the ortho position of meso-phenyl groups, exhibit propensity for intramolecular hydrogen bonding important for the design of supramolecular structures with tight conformations (Orlowski et al. 2017b). Therefore, we select an FB trans- $\mathrm{A}_{2} \mathrm{~B}$-corrole with an $o-\mathrm{C}_{6} \mathrm{H}_{4}-\mathrm{OCH}_{2} \mathrm{CONH}-\mathrm{R}$ mesosubstituent containing L-phenylalanine, i.e., $-\mathrm{R}=-\mathrm{C}^{(\mathrm{S})} \mathrm{H}(-$ $\left.\mathrm{CH}_{2}-\mathrm{C}_{6} \mathrm{H}_{5}\right)-\mathrm{CO}_{2} \mathrm{CH}_{3}$, i.e., $\mathbf{C o r}\left(\mathbf{H}_{3}\right)$-Phe (Scheme 1). Linking these porphyrinoids to amino acids and peptides offers building blocks for biomimetic and bioinspired charge-transfer systems (Vullev 2011). Following a classical procedure for peptide synthesis allows us to prepare $\operatorname{Cor}\left(\mathbf{H}_{3}\right)$-Phe from corrole 1 and L-phenylalanine methyl ester (2) in 62\% yield after purifying with column chromatography (Scheme 1).

Multiple treatments of $\mathbf{C o r}\left(\mathbf{H}_{3}\right)$-Phe dissolved in a chlorinated solvent with $\mathrm{D}_{2} \mathrm{O}$ drives the exchange of the amide, $\mathrm{H}_{a}$, and the three pyrrole $\mathrm{N}-\mathrm{H}$ protons with deuterium to obtain $\operatorname{Cor}\left(\mathbf{D}_{\mathbf{3}}\right)$-Phe (Fig. 1a, b). NMR spectroscopy allows for monitoring the replacement of these protons with deuteriums. After treatments with $\mathrm{D}_{2} \mathrm{O}$, and prior to the optical measurements, we acquire the ${ }^{1} \mathrm{H}$ NMR spectra of the samples in a volatile deuterated solvent, such as $\mathrm{CDCl}_{3}$, to confirm the proton-to-deuterium exchange. Fast evaporation of the volatile $\mathrm{CDCl}_{3}$ in vacuo at room temperature leaves the solid $\operatorname{Cor}\left(\mathbf{D}_{3}\right)$-Phe that we dissolve in a spectroscopygrade non-polar solvent. With $\mathrm{N}-\mathrm{H} \mathrm{p} K_{a}<7$ (Ghosh 2017), the pyrrole protons are quite labile and not always detectable in an NMR solvent even with moderate polarity. Also, these protons are in the middle of the ring current, induced in the corrole macrocycle, and they exhibit pronounced shielding effects with chemical shifts between 0 and -6 ppm for toluene- $d_{8}$ (Bocian et al. 2015). Nevertheless, we monitor the 

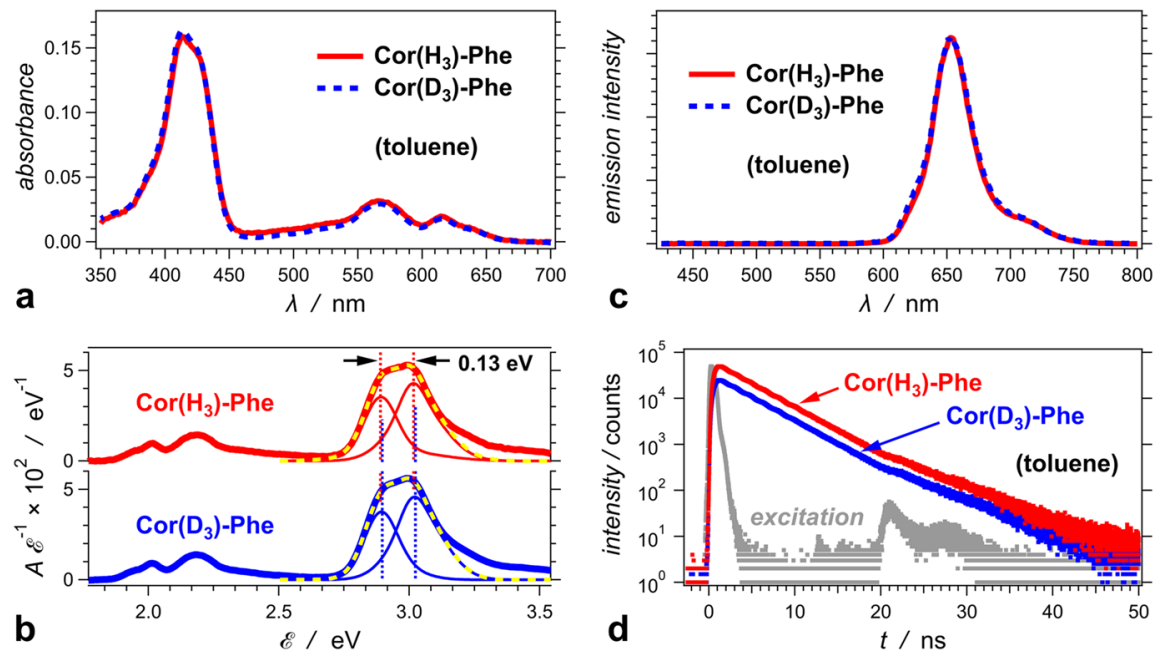

Fig. 2 Optical absorption and emission properties of $\mathbf{C o r}\left(\mathbf{H}_{3}\right)$-Phe and $\operatorname{Cor}\left(\mathbf{D}_{3}\right)$-Phe for toluene media. a Optical absorption spectra of $1.5 \mu \mathrm{M}$ corrole samples. b The optical absorption spectra plotted against energy abscissa. The recorded $A(\lambda)$ spectra are converted to A(E) as previously described (Angulo et al. 2006). The Soret band at $3 \mathrm{eV}$ is deconvoluted by fitting it to a sum of Gaussians. The yellow dashed lines represent the data fits, and the thin lines show the comprising components of the band. c Fluorescence spectra of the protonated and the deuterated corrole conjugate; $\lambda_{e x}=415 \mathrm{~nm}$; and $\phi_{f}$ of $\operatorname{Cor}\left(\mathbf{H}_{3}\right)$-Phe and $\operatorname{Cor}\left(\mathbf{D}_{3}\right)$-Phe is 0.15 and 0.13 , respectively. d Fluorescence decays of the protonated and the deuterated corrole conjugate recorded using TCSPC; $\lambda_{e x}=406 \mathrm{~nm}$; half-height excita-

amide proton, $\mathrm{H}_{a}$, in $\mathbf{C o r}\left(\mathbf{H}_{\mathbf{3}}\right)$-Phe (Fig. 1a), which disappear from the ${ }^{1} \mathrm{H}$ NMR spectrum upon deuterium exchange (Fig. 1e). Because amide protons are less labile than the pyrrole $\mathrm{N}-\mathrm{H}$ protons, the replacement of $\mathrm{H}_{a}$ with $\mathrm{D}_{a}$ (Fig. 1a, b) ensures that the pyrrole $\mathrm{N}-\mathrm{H}$ protons are also replaced with deuteriums.

The relatively low $\mathrm{p} K_{a}$ of the pyrrole $\mathrm{N}-\mathrm{H}$ groups further decreases upon photoexcitation. In order to prevent deprotonation of the corrole pyrroles, especially when in excited state, this pronounced acidity renders the use of polar solvents, along with non-polar Lewis bases, unfeasible. Furthermore, FB corroles have a propensity for photodegradation in polar media, such as acetonitrile, as the teams of Gryko and Danikiewicz demonstrate using mass spectrometry (Swider et al. 2010). Selection of an aromatic non-polar solvent, such as toluene, ensures sufficient solubility of the corrole conjugates while suppressing the deprotonation and photodegradation of these contracted FB porphyrinoids.

\section{Optical properties}

Typical for porphyrinoids, the optical absorption spectrum of $\operatorname{Cor}\left(\mathbf{H}_{3}\right)$-Phe shows a Soret band stretching between about 380 and $440 \mathrm{~nm}$, and Q-bands spreading between 500 and $650 \mathrm{~nm}$ (Fig. 2a). The shape of the Soret band indicates

tion pulse width $=200 \mathrm{ps}$; and $\tau$ of $\operatorname{Cor}\left(\mathbf{H}_{3}\right)$-Phe and $\operatorname{Cor}\left(\mathbf{D}_{\mathbf{3}}\right)$-Phe is $4.2 \mathrm{~ns}$ and $4.3 \mathrm{~ns}$, respectively. For improved visualization, the ordinate for the emission decay of $\operatorname{Cor}\left(\mathbf{H}_{3}\right)$-Phe is set from 1 to $10^{5}$ counts, and for $\operatorname{Cor}\left(\mathbf{D}_{3}\right)$-Phe-from 2 to $2 \times 10^{5}$ counts. The secondary excitation pulse at $20-30 \mathrm{~ns}$ is an instrumental artifact, most likely originating from ringing due to an impedance mismatch in circuits and electric connections. Nevertheless, the intensity of this secondary excitation pulse is about $0.1 \%$ of the intensity of the initial excitation and does not considerably affect the decay curves. Furthermore, the deconvolution algorithm accounts for this weak secondary excitation pulse and does not affect the extracted lifetimes from the measured decays

that it comprises two principal peaks. Spectral deconvolution reveals that these two components are separated by about $0.13 \mathrm{eV}$ (Fig. 2b), which can be ascribed to $\mathrm{S}_{0} \rightarrow \mathrm{S}_{2}$ transitions of two tautomers (Szymanski et al. 2014; Kruk et al. 2012; Ding et al. 2005).

The fluorescence of $\operatorname{Cor}\left(\mathbf{H}_{3}\right)$-Phe shows a spectral band consistent with the radiative deactivation of T1 (Fig. 2c) (Szymanski et al. 2014; Kruk et al. 2012; Ventura et al. 2005; Ding et al. 2005). The modest fluorescence quantum yields, $\phi_{f}=0.15$, along with the nanosecond excited-state lifetime, $\tau=4.2 \mathrm{~ns}$ (Fig. 2d), reveals non-radiative decay rates, $k_{n r}=2 \times 10^{8} \mathrm{~s}^{-1}$, that are about six times larger than the radiative ones.

Replacing the pyrrole protons with deuteriums does not noticeably affect the steady-state optical spectra of the corrole conjugate (Fig. 2a-c). That is, deuteration does not noticeably alter the distribution of the ground-state tautomer populations in non-polar liquid media at room temperature. As estimated from emission decays recorded using timecorrelated single-photon counting (TCSPC), the excitedstate lifetimes of $\operatorname{Cor}\left(\mathbf{H}_{3}\right)$-Phe and $\operatorname{Cor}\left(\mathbf{D}_{3}\right)$-Phe are practically the same (Fig. 2d). This lack of detectable kinetic isotope effects indicate that the $\mathrm{N}-\mathrm{H}$ vibrational modes in $\operatorname{Cor}\left(\mathbf{H}_{3}\right)$-Phe are not deterministic for the deactivation of its lowest singlet excited state. The lack of isotope effects on 

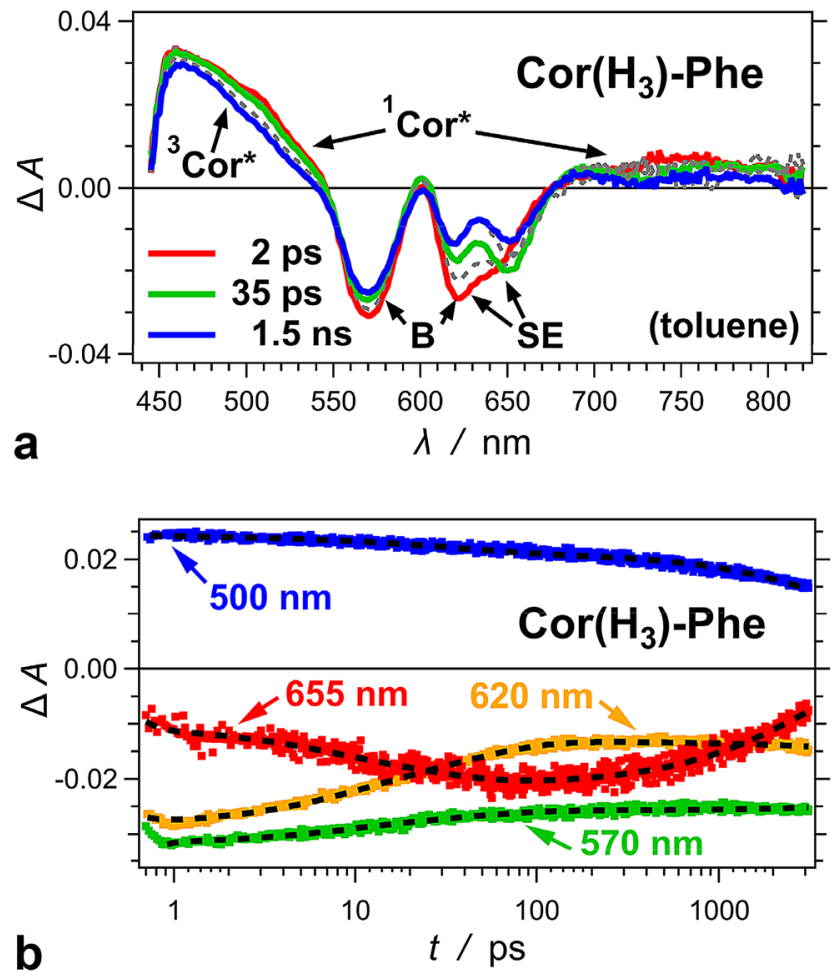

b

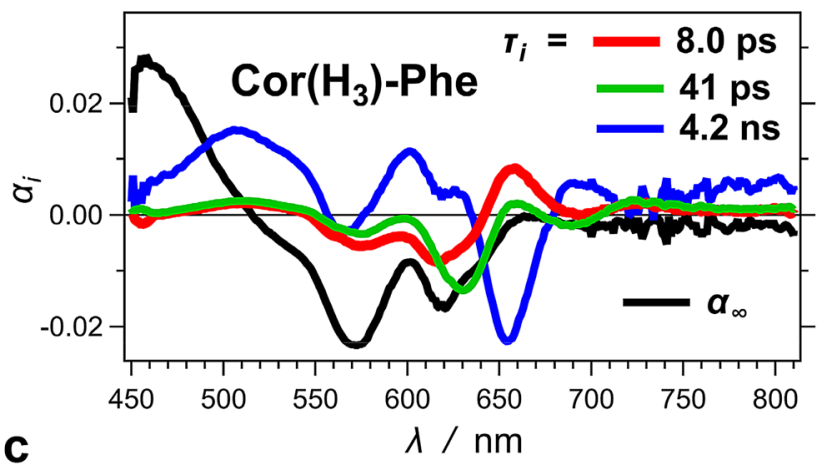

Fig. 3 Transient-absorption dynamics of $\operatorname{Cor}\left(\mathbf{H}_{3}\right)$-Phe and $\operatorname{Cor}\left(\mathbf{D}_{3}\right)$ Phe for toluene media; $\lambda_{e x}=400 \mathrm{~nm}$; pulse width $=50 \mathrm{fs}$. a, $\mathbf{d}$ TA spectra showing the absorption features of ${ }^{1} \mathrm{Cor}^{*}$ and ${ }^{3} \mathrm{Cor}^{*}$, as well as the ground-state bleach (B) and the stimulated emission (SE). For clarity, only the spectra at picosecond (1-2 ps), tens of picosecond (35-50 ps), and nanosecond (1-3 ns) times are displayed in color. Additional TA spectra at intermediate timepoints are depicted in the background with gray dashed lines. b, e TA kinetic traces recorded at $500 \mathrm{~nm}$, where ${ }^{1}$ Cor* $^{*}$ and ${ }^{3}$ Cor* absorb; $570 \mathrm{~nm}$, where the B is

the measured nanosecond dynamics at room temperature, however, is not necessarily informative about the picosecond excited-state transformations.

\section{Transient-absorption dynamics}

Optical TA spectra of $\mathbf{C o r}\left(\mathbf{H}_{3}\right)$-Phe reveal a broad absorption band stretching between 450 and $550 \mathrm{~nm}$ (Fig. 3a). It is typical for the overlapping absorptions of the singlet and
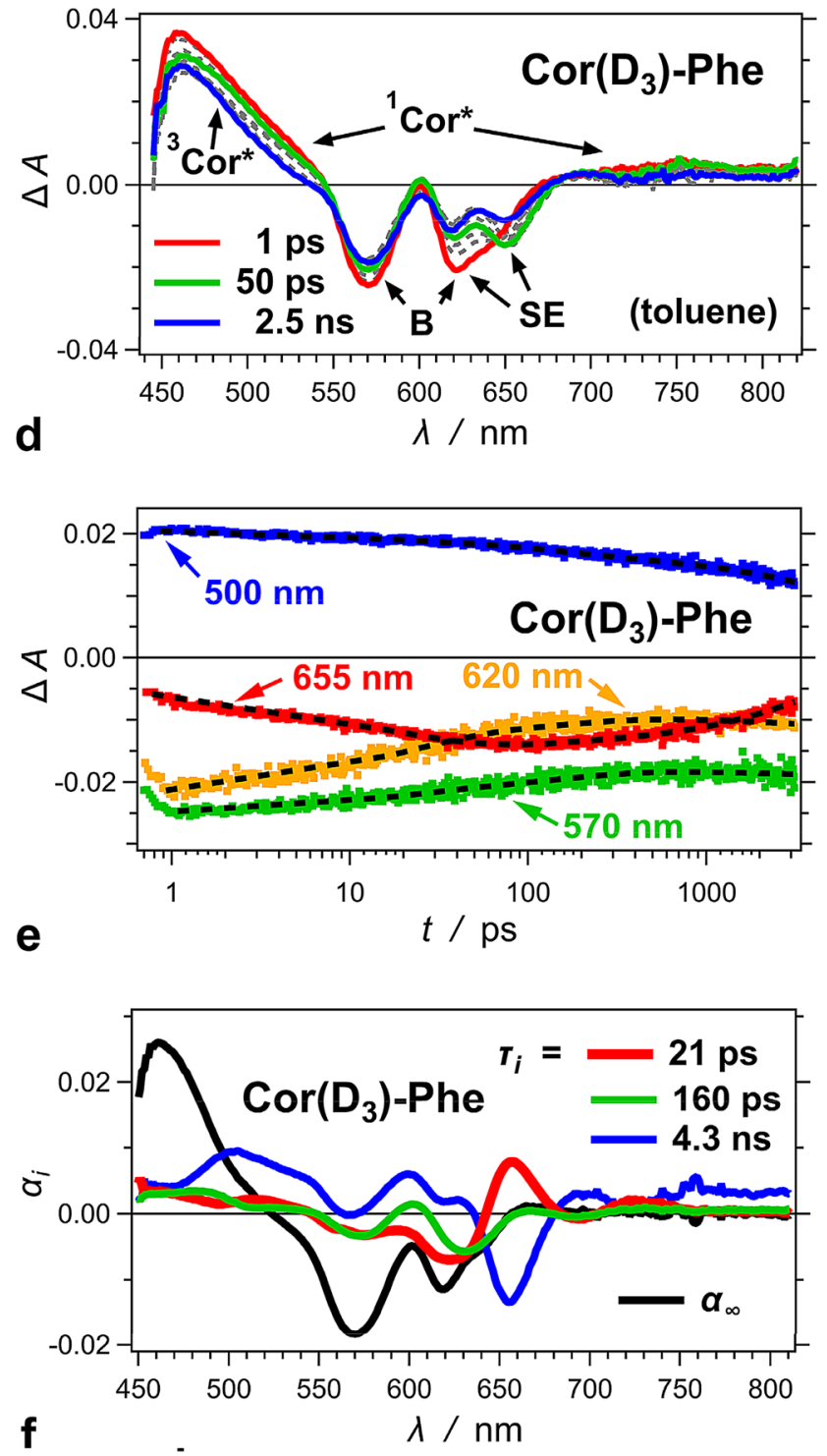

prevalent and has some overlap with the TA of ${ }^{1}$ Cor*; $620 \mathrm{~nm}$, where B and SE overlap; and $655 \mathrm{~nm}$, where SE corresponds to the fluorescence maximum. The dashed lines represent the global fits. c, f Amplitude spectra obtained from global-fit analysis (Eq. 1), aided by single value decomposition, showing the picosecond and nanosecond transitions, as well as the long-lived ${ }^{3}$ Cor* along with the B depicted by $\alpha_{\infty}$ vs. $\lambda$. The nanosecond time constants, i.e., 4.2 and $4.3 \mathrm{~ns}$, are obtained from the fluorescence decays (Fig. 2d) and introduced to the global-fit algorithm with their values held

triplet excited-state transients of corroles (Flamigni et al. 2008; Flamigni and Gryko 2009; Tasior et al. 2008). In addition, the singlet transient, ${ }^{1}$ Cor*, manifests weak broad TA in the near-infrared (NIR) spectral region (Fig. 3a). The negative $\Delta A$ peaks are consistent with the ground-state bleach (B) and the stimulated emission (SE) of corroles (Fig. 3a). The 650-nm SE peak matches the steady-state fluorescence that originates from the T1 tautomer (Fig. 2c). Nevertheless, the ${ }^{1} \mathrm{~T} 2 *$ tautomer exhibits hypsochromically shifted emission 
(Kruk et al. 2012) that is most plausibly responsible for an SE signal at the early timepoint around $620 \mathrm{~nm}$ (Fig. 3a). The bleach, B, at $570 \mathrm{~nm}$ undergoes about $13 \%$ recovery within the first $35 \mathrm{ps}$ after the excitation. At $620 \mathrm{~nm}$, on the other hand, the negative amplitude of the signal shows a $34 \%$ decrease within the first 35 ps (Fig. 3a). This discrepancy precludes that the bleach recovery by itself is solely responsible for the early dynamics of the signal around $620 \mathrm{~nm}$ and renders a principal contribution of the SE from the ${ }^{1} \mathrm{~T} 2 *$ excited state as a plausibility.

The TA dynamics is consistent with the nanosecond deactivation of ${ }^{1}$ Cor*, as the bleach recovery and the TA decays in the blue and NIR spectral regions reveal (Fig. 3b). The lack of significant decrease in $\Delta A$ of the $450-550-\mathrm{nm}$ TA band suggests for comparable molar extinction coefficients of ${ }^{1}$ Cor* and ${ }^{3}$ Cor* in this spectral region, along with a relatively high quantum yield of intersystem crossing (ISC), $\phi_{\text {ISC }}$. The nanosecond magnitude of $k_{n r}{ }^{-1}$ precludes the option for femtosecond and picosecond ISC observed for other triplet-forming chromophores (Zugazagoitia et al. 2008; Espinoza et al. 2016).

The SE bands reveal the most interesting feature of the picosecond TA dynamics. At the fluorescence maximum, i.e., at $655 \mathrm{~nm}$, the intensity of SE shows a picosecond increase, followed by a nanosecond decrease (Fig. 3b). Concurrently, the bands at $620 \mathrm{~nm}$ and $570 \mathrm{~nm}$ show a decrease in $-\Delta A$ with the same picosecond time scales. These changes are consistent with ${ }^{1} \mathrm{~T} 2 * \rightarrow{ }^{1} \mathrm{~T} 1 *$ tautomerization. The growth of the SE fluorescence band associates with T1 and accompanies a drop of hypsochromically shifted SE ascribed to $\mathrm{T} 2$.

The behavior of the $-\Delta A$ bands at 570 and $620 \mathrm{~nm}$ at $t>100 \mathrm{ps}$ is consistent with an overlap of the ground-state bleach with the TA of ${ }^{1}$ Cor*. The nanosecond deactivation of ${ }^{1}$ Cor* proceeds along three parallel pathways: (1) a radiative decay $(\mathrm{F})$; (2) a non-radiative decay via internal conversion (IC); and (3) another non-radiative route, via ISC. While all these pathways lead to a decrease in the ${ }^{1}$ Cor* TA, i.e., making $\Delta A$ more negative, only $\mathrm{F}$ and IC lead to recovery of the ground state and making $\Delta A$ more positive. Therefore, the balance between the absorptivity of ${ }^{1}$ Cor and ${ }^{1}$ Cor*, along with the magnitude of $\phi_{\text {ISC }}$, determines weather $\Delta A$ at these wavelengths exhibits positive or negative nanosecond shifts or just remains constant.

To quantify the observed picosecond excited-state dynamics, we resort to global-fit analysis of the TA results (Fig. 3c):

$\Delta A(\lambda, t)=\alpha_{\infty}(\lambda)+\Sigma_{i} \alpha_{i}(\lambda) \exp \left(-t \tau_{i}^{-1}\right)$

where we hold the time constants, $\tau_{i}$, which is the same for different wavelengths. A positive amplitude, i.e., $\alpha_{i}(\lambda)>0$, indicates a negative $\Delta A$ shift at that wavelength, which is
Table 1 Rate constants of the picosecond and nanosecond excitedstate dynamics of $\operatorname{Cor}\left(\mathbf{H}_{3}\right)$-Phe and $\operatorname{Cor}\left(\mathbf{D}_{3}\right)$-Phe

\begin{tabular}{lllll}
\hline & $\begin{array}{l}k_{i}^{*} \times 10^{-9} / \mathrm{s}^{-1} \\
\left(\alpha_{i}\right)^{\mathrm{a}}\end{array}$ & $\mathrm{KIE}_{i}^{* \mathrm{~b}}$ & $k_{d} \times 10^{-9} / \mathrm{s}^{-1 \mathrm{c}}$ & $\mathrm{KIE}_{d}^{\mathrm{b}}$ \\
\hline $\mathrm{Cor}\left(\mathrm{H}_{3}\right)-\mathrm{Phe}$ & $130 \pm 20(0.44)$ & & $0.24 \pm 0.01$ & \\
& $24 \pm 1(0.66)$ & & & \\
$\mathrm{Cor}\left(\mathrm{D}_{3}\right)-\mathrm{Phe}$ & $48 \pm 3(0.63)$ & $2.7 \pm 0.4$ & $0.23 \pm 0.01$ & $1.04 \pm 0.06$ \\
& $6.3 \pm 0.5(0.47)$ & $3.8 \pm 0.3$ & & \\
\hline
\end{tabular}

${ }^{\mathrm{a}}$ Rate constants representing the picosecond dynamics dominated by ${ }^{1} \mathrm{~T} 2 * \longrightarrow{ }^{1} \mathrm{~T} 1 *$ transitions, along with the relative amplitudes in the parentheses, i.e., $\alpha_{i}=\Delta A_{i,(620 \mathrm{~nm}, 0 \mathrm{ps})} \Sigma_{j} \Delta A_{j,(620 \mathrm{~nm}, 0 \mathrm{ps})}$

${ }^{\mathrm{b}}$ Kinetic isotope effects obtained from comparison of the rate constants for $\operatorname{Cor}\left(\mathbf{H}_{3}\right)$-Phe $\left(k^{(\mathrm{H})}\right)$ and $\operatorname{Cor}\left(\mathbf{D}_{3}\right)$-Phe $\left(k^{(\mathrm{D})}\right)$, i.e., $\mathrm{KIE}_{i}=k_{i}^{(\mathrm{H})} / k_{i}^{(\mathrm{D})}$. The error bars, $\delta \mathrm{KIE}$, are obtained from the error bars for the rate constants, $\delta k$, i.e., $\delta \mathrm{KIE}_{i}=\mathrm{KIE}_{i}\left(\left(\delta k_{i}^{(\mathrm{H})} /\right.\right.$ $\left.\left.k_{i}^{(\mathrm{H})}\right)^{2}+\left(\delta k_{i}^{(\mathrm{D})} / k_{i}^{(\mathrm{D})}\right)^{2}\right)^{-2}$

${ }^{\mathrm{c}}$ Rate constants for the deactivation of the $\mathrm{S}_{1}$ states are obtained from the fluorescence decays of the two conjugates (Fig. 2d)

consistent with TA decay or a growth of SE or B signals. Conversely, a negative amplitude shows a positive $\Delta A$ shift, i.e., a TA rise or a decrease in the intensity of SE or $\mathrm{B}$ signals. In addition, $\alpha_{\infty}(\lambda) \neq 0$ is suggested for long-lived transients with decays that are considerably slower than the dynamic range of the pump-probe technique.

The amplitude spectra show biexponential picosecond dynamics consistent with a growth of SE at $655 \mathrm{~nm}$ as a concurrent decrease in hypsochromic emission signal at about $620 \mathrm{~nm}$ (Fig. 3c). Small changes in the bleach at about $570 \mathrm{~nm}$ and the TA of ${ }^{1}$ Cor* can be ascribed to spectral shifts. In a good agreement with tautomerization, these results show heterogeneous kinetics with timescales of about 10-40 ps (Fig. 3c, Table 1).

The heterogeneity of the kinetics representing this excited-state transformation reveals another important feature of $\operatorname{Cor}\left(\mathbf{H}_{3}\right)$-Phe. For clarity of the presentation, in this publication, we describe the excited-state transitions in terms of two tautomers, T1 and T2, as previously described for corroles with $C_{s}$ symmetry (Kruk et al. 2012; Szymanski et al. 2014; Ding et al. 2005). Hydrogen bonding between the glycolamide substituent and the pyrroles, however, can further break the symmetry and increase the number of discernable tautomeric structures. Excluding its hypsochromic shoulder, the Soret ground-state absorption band shows at least two principle components (Fig. 2b). Also, we cannot rule the possibility of different tautomers with closely similar energies of their $\mathrm{S}_{0} \rightarrow \mathrm{S}_{n}$ transitions. In addition, the emission spectrum of $\operatorname{Cor}\left(\mathbf{H}_{3}\right)$-Phe unequivocally shows the features of the $\mathrm{T} 1$ fluorescence. Therefore, the two-tautomer model provides a good approximation for describing the optical properties of $\operatorname{Cor}\left(\mathbf{H}_{3}\right)$-Phe. The heterogeneity of the picosecond dynamics, however, points to a removal of degeneracy that intramolecular hydrogen 
bonding induces in $\mathbf{C o r}\left(\mathbf{H}_{3}\right)$-Phe. Placing three protons on four pyrrole nitrogens defines two degenerate structures of T1 where the deprotonation of pyrrole A and pyrrole D is equivalent (Fig. 1; and two degenerate structures of T2, i.e., with equivalence of deprotonated pyrroles B and C (Fig. 1). Intramolecular hydrogen bonding between the glycolamide and one of the pyrroles makes the two structures of T2 (and T1) different.

\section{Kinetic isotope effects}

The TA spectra of the deuterated conjugate, $\operatorname{Cor}\left(\mathbf{D}_{3}\right)$-Phe, show the same absorption, B, and SE feature as those of $\operatorname{Cor}\left(\mathbf{H}_{3}\right)$-Phe (Fig. 3d). While the overall TA kinetic traces (Fig. 3b, e) and global-fit amplitude spectra (Fig. 3c, f) appear similar for the protonated and deuterated conjugates, the principal differences are in the picosecond dynamics.

The trace at $655 \mathrm{~nm}$, ascribed to the T1 fluorescence, shows faster SE growth for $\operatorname{Cor}\left(\mathbf{H}_{3}\right)$-Phe than for $\operatorname{Cor}\left(\mathbf{D}_{3}\right)$ Phe (Fig. 3c, f). Similarly, the deuteration slows down the picosecond dynamics depicted at $620 \mathrm{~nm}$. The global-fit analysis reveals biexponential picosecond kinetics for $\operatorname{Cor}\left(\mathbf{D}_{3}\right)$-Phe that is about three to four times slower than that for $\operatorname{Cor}\left(\mathbf{H}_{3}\right)$-Phe (Fig. 3c, f).

The kinetic isotope effect (KIE) when comparing the rate constants of the fast components of the picosecond dynamics of $\operatorname{Cor}\left(\mathbf{H}_{3}\right)$-Phe and $\operatorname{Cor}\left(\mathbf{D}_{3}\right)$-Phe amounts to 2.7. Similarly, for the slow components, KIE $=3.8$ (Table 1). The magnitude of these KIE values indicate that the proton vibrational modes have direct contributions to the transitions observed in the picosecond time domain, which is consistent with ascribing them to excited-state tautomerization.

Despite the large KIE for the picosecond dynamics, we do not detect KIE in the nanosecond deactivation of the emissive excited state (Fig. 2d), i.e., KIE $<1.05$ (Table 1). This outcome indicates that the picosecond tautomerization relaxes fast enough the excited states to ${ }^{1} \mathrm{~T} 1 *$ type of a structure, which is solely responsible for the basic photophysics of $\operatorname{Cor}\left(\mathbf{H}_{3}\right)$-Phe. Under the employed conditions, the direct deactivation of high-energy tautomers to the ground state does not have detectible contributions to the observed nanosecond photophysics, which is consistent with Kasha's rule (Kasha 1950).

\section{Conclusion}

The foundation of the Kasha's rule originates from the common trend that the coupling between electronically excited states tends to be inherently stronger than their coupling with the ground state. Hence, the relaxation of upper excited states to the lowest excited one, within the same multiplicity manifold, is much faster than the direct transitions from them to the ground state. In organic chromophores, therefore, most photoinduced reactions commence from the lowest singlet excited state. Femtosecond processes from upper excited states, important for generating hot electrons and holes, for example, can successfully compete with the internal conversion to the lowest excited state. Free-base corroles reveal a slightly different paradigm. The picosecond excited-state tautomerization, responsible for relaxation of about $0.1 \mathrm{eV}$, is fast enough so that the nanosecond deactivation processes occur from the structure with the lowest energy in the singlet manifold. Nevertheless, the proton transfer involved in the tautomerization is most often inherently slower than internal conversion between electronically excited states. Therefore, picosecond and sub-picosecond charge and energy transfer can readily occur from high-energy tautomers benefiting from the extra $100 \mathrm{meV}$ thermodynamic driving forces. This characteristic of free-base corroles can be extended to other porphyrinoids (Thomas et al. 2020) and illustrates alternative paradigms in the design of artificial photosynthesis with broad applicability to a range of chromophores exhibiting such excited-state behavior.

\section{Materials and methods}

\section{Synthesis}

Reaction was carried out in flame-dried glassware in argon atmosphere. Required chemicals, including L-phenylalanine methyl ester (2), were purchased from Sigma-Aldrich and used without further purification. DMF was dried using solvent purification system. Corrole $\mathbf{1}$ was prepared according to a reported procedure (Orlowski et al. 2015). The reaction progress was monitored by thin layer chromatography (TLC, aluminum plates coated with silica gel, Merck 60, F-254) and visualized via UV lamp. The ${ }^{1} \mathrm{H}$ NMR spectrum was measured at temperature $298 \mathrm{~K}$ in $\mathrm{CDCl}_{3}$ (if not otherwise stated) solutions with a Varian vnmrs-600, using tetramethylsilane (TMS) as internal standard.

\section{$\operatorname{Cor}\left(\mathrm{H}_{3}\right)$-Phe (Scheme 1)}

1 (50 mg, $0.064 \mathrm{mmol})$, HATU (24 mg, $0.064 \mathrm{mmol}$ ), and DIPEA ( $17 \mu \mathrm{L}, 0.096 \mathrm{mmol})$ were dissolved in dry DMF $(18 \mathrm{~mL})$ and stirred for $30 \mathrm{~min}$ under argon atmosphere. Subsequently, L-phenylalanine methyl ester (2) $(0.064 \mathrm{mmol})$ was added and the resulting solution was stirred for $2 \mathrm{~h}$. The crude reaction mixture was purified by column chromatography (silica, $1 \%$ methanol in DCM) and recrystallized from diethyl ether to produce $37 \mathrm{mg}$ of dark red crystals of $\mathbf{C o r}\left(\mathbf{H}_{3}\right)$-Phe (62\% yield). ${ }^{1} \mathrm{H}$ NMR $(600 \mathrm{MHz}$, DMF-d $\left._{6}\right) \delta(\mathrm{ppm}): 9.36-9.17(\mathrm{~m}, 2 \mathrm{H}), 9.13-8.54(\mathrm{~m}, 4 \mathrm{H})$, 
8.72-8.53 (m, 2H), 8.14-8.07 (m, 1H), 7.85-7.76 (m, 1H), 7.52-7.45 (m, 1H), 7.44-7.37 (m, 1H), 6.72-6.04 (m, 4H), 5.99-5.57 (m, 2H), 4.58-4.36 (m, 2H), 4.06-3.96 (m, 1H), 3.29-3.03 (bs, 3H), 2.17-1.97 (m, 1H), and 1.90-1.32 (m, 1H). HRMS (ESI/TOF) $\mathrm{m} / z$ : $[\mathrm{M}-\mathrm{H}]^{-}$Calcd. for $\mathrm{C}_{49} \mathrm{H}_{28} \mathrm{~F}_{10} \mathrm{~N}_{5} \mathrm{O}_{4}^{-}$940.1982; Found 940.1959.

\section{$\operatorname{Cor}\left(D_{3}\right)-$ Phe}

$1 \mathrm{mg}$ of $\mathbf{C o r}\left(\mathbf{H}_{3}\right)$-Phe was dissolved in $1 \mathrm{~mL} \mathrm{CDCl}_{3}$ and its ${ }^{1} \mathrm{H}$ NMR spectrum was recorded. Addition of $0.5 \mathrm{~mL} \mathrm{D}_{2} \mathrm{O}$ was followed by shaking the mixture for $5 \mathrm{~min}$, and after the phases were allowed to separate, the aqueous layer was pipetted out. The procedure was repeated three times, the proton-to-deuterium exchange was confirmed using NMR spectroscopy (Fig. 1e), the solvent was evaporated in vacuo, and the obtained dry $\operatorname{Cor}\left(\mathbf{D}_{\mathbf{3}}\right)$-Phe was dissolved in toluene for spectroscopy studies. For the solvent, using toluene dried over $\mathrm{N}_{2} \mathrm{SO}_{4}$, and toluene that was washed several times with $\mathrm{D}_{2} \mathrm{O}$, does not result in detectable differences in the transient-absorption spectroscopy.

\section{Steady-state optical spectroscopy}

The absorbance spectra were recorded using a JASCO V-670 UV/Visible/NIR spectrophotometer (Tokyo, Japan). Fluorescence measurements were conducted with a Horiba Jobin Yvon Fluorolog-3-22 spectrofluorometer (NJ, USA) (Lu et al. 2010; Chau et al. 2011; Gupta et al. 2013). All samples were purged with argon prior to each measurement. The absorbance at the excitation wavelengths was kept within the range between 0.1 and 0.2 for recording the spectra used for calculating the emission quantum yields (Demas and Crosby 1971; Wan et al. 2008; Jung et al. 2014; Jones et al. 1995).

\section{Time-resolved optical emission spectroscopy}

Time-correlated single-photon counting (TCSPC) experiments were conducted using Horiba Jobin Yvon Fluorolog-3-22 spectrofluorometer (Tokyo, Japan)). Pulsed laser diode, NanoLED, provided the excitation at $406 \mathrm{~nm}$ at a repetition frequency of $1 \mathrm{MHz}$ and half-height pule width of 200 ps (Krzeszewski et al. 2018; Ghazinejad et al. 2012; Espinoza et al. 2018). Data fits of the emission decays, employing deconvolution with a monoexponential function, yielded the singlet excited-state lifetimes.

\section{Transient-absorption spectroscopy}

A Helios pump-probe spectrometer (Ultrafast Systems, LLC, Florida, USA) was used in a transmission mode. 800 -nm pulses ( $\geq 35 \mathrm{fs}, 4.0 \mathrm{~mJ}$ per pulse, at $1 \mathrm{kHz}$ ) were generated by a SpitFire Pro $35 \mathrm{~F}$ regenerative amplifier (Spectra Physics, Newport, CA, USA). The amplifier was pumped with an Empower 30 Q-switched laser ran at $20 \mathrm{~W}$. A MaiTai SP oscillator provided the seed pulses with 55-nm bandwidth. The wavelength of the pump was tuned using an optical parametric amplifier, OPA-800CU (Newport Corporation, Newport, CA, USA), equipped with harmonic generators. Responses from pure solvents were used for the chirp correction of the transient-absorption data. The data analysis was carried out using Surface Xplorer (Ultrafast Systems, LLC, Florida, USA) and IgorPro v. 8 (WaveMetrics, Inc., Lake Oswego, OR, USA) (Purc et al. 2016; Bao et al. 2014; Upadhyayula et al. 2015; Gray et al. 2017; Guo et al. 2013).

Supplementary Information The online version contains supplementary material available at https://doi.org/10.1007/s11120-021-00824-4.

Acknowledgements The authors would like to thank the USA National Science Foundation (Grant CHE 1800602, along with AGEP supplement for J.A.C.) and the Polish National Science Centre (Grant HARMONIA UMO-2018/30/M/ST5/00460) for funding this work.

\section{Declaration}

Conflict of interest The authors declare that they have no conflicts of interest.

Open Access This article is licensed under a Creative Commons Attribution 4.0 International License, which permits use, sharing, adaptation, distribution and reproduction in any medium or format, as long as you give appropriate credit to the original author(s) and the source, provide a link to the Creative Commons licence, and indicate if changes were made. The images or other third party material in this article are included in the article's Creative Commons licence, unless indicated otherwise in a credit line to the material. If material is not included in the article's Creative Commons licence and your intended use is not permitted by statutory regulation or exceeds the permitted use, you will need to obtain permission directly from the copyright holder. To view a copy of this licence, visit http://creativecommons.org/licenses/by/4.0/.

\section{References}

Agadjanian H, Ma J, Rentsendorj A, Valluripalli V, Hwang JY, Mahammed A, Farkas DL, Gray HB, Gross Z, Medina-Kauwe LK (2009) Tumor detection and elimination by a targeted gallium corrole. Proc Natl Acad Sci USA 106(15):6105-6110. https://doi.org/10.1073/pnas.0901531106

Angulo G, Grampp G, Rosspeintner A (2006) Recalling the appropriate representation of electronic spectra. Spectrochim Acta A 65(3-4):727-731. https://doi.org/10.1016/j.saa.2006.01.007 
Aviv-Harel I, Gross Z (2009) Aura of corroles. Chemistry 15(34):8382-8394. https://doi.org/10.1002/chem.200900920

Bao D, Upadhyayula S, Larsen JM, Xia B, Georgieva B, Nunez V, Espinoza EM, Hartman JD, Wurch M, Chang A, Lin C-K, Larkin J, Vasquez K, Beran GJO, Vullev VI (2014) Dipolemediated rectification of intramolecular photoinduced charge separation and charge recombination. J Am Chem Soc 136(37):12966-12973. https://doi.org/10.1021/ja505618n

Bocian W, Paluch P, Nowak-Krol A, Gryko DT, Potrzebowski M, Sniechowska J, Sitkowski J, Bednarek E, Kozerski L (2015) The $1 \mathrm{H}, 13 \mathrm{C}, 15 \mathrm{~N}$, and $19 \mathrm{~F}$ NMR chemical shifts assignments in 5,10,15-tris (pentafluorophenyl)tetra-15N corrole at $191 \mathrm{~K}$. Magn Reson Chem 53(2):167-171. https://doi.org/10.1002/ mrc. 4145

Chandler NJ, Greener ID, Tellez JO, Inada S, Musa H, Molenaar P, DiFrancesco D, Baruscotti M, Longhi R, Anderson RH, Billeter R, Sharma V, Sigg DC, Boyett MR, Dobrzynski H (2009) Molecular architecture of the human sinus node insights into the function of the cardiac pacemaker. Circulation 119(12):1562-1575. https ://doi.org/10.1161/circulationaha.108.804369

Chau K, Millare B, Lin A, Upadhyayula S, Nuñez V, Xu H, Vullev VI (2011) Dependence of the quality of adhesion between poly(dimethylsiloxane) and glass surfaces on the composition of the oxidizing plasma. Microfluid Nanofluid 10(4):907-917

Demas JN, Crosby GA (1971) Measurement of photoluminescence quantum yields. Review. J Phys Chem 75(8):991-1024. https:// doi.org/10.1021/j100678a001

Ding T, Aleman EA, Modarelli DA, Ziegler CJ (2005) Photophysical properties of a series of free-base corroles. J Phys Chem A 109(33):7411-7417. https://doi.org/10.1021/jp052047i

Dogutan DK, Stoian SA, McGuire R, Schwalbe M, Teets TS, Nocera DG (2011) Hangman corroles: efficient synthesis and oxygen reaction chemistry. J Am Chem Soc 133(1):131-140. https://doi. org/10.1021/ja108904s

Einrem RF, Gagnon KJ, Alemayehu AB, Ghosh A (2016) Metalligand misfits: facile access to rhenium-oxo corroles by oxidative metalation. Chemistry 22(2):517-520. https://doi.org/10.1002/ chem.201504307

Espinoza EM, Clark JA, Derr JB, Bao D, Georgieva B, Quina FH, Vullev VI (2018) How do amides affect the electronic properties of pyrene? ACS Omega 3(10):12857-12867. https://doi. org/10.1021/acsomega.8b01581

Espinoza EM, Xia B, Darabedian N, Larsen JM, Nunez V, Bao D, Mac JT, Botero F, Wurch M, Zhou F, Vullev VI (2016) Nitropyrene photoprobes: making them, and what are they good for? Eur J Org Chem 2:343-356. https://doi.org/10.1002/ejoc.201501339

Flamigni L, Gryko DT (2009) Photoactive corrole-based arrays. Chem Soc Rev 38(6):1635-1646. https://doi.org/10.1039/b805230c

Flamigni L, Ventura B, Tasior M, Becherer T, Langhals H, Gryko DT (2008) New and efficient arrays for photoinduced charge separation based on perylene bisimide and corroles. Chemistry 14(1):169-183. https://doi.org/10.1002/chem.200700866

Ghazinejad M, Kyle JR, Guo S, Pleskot D, Bao D, Vullev VI, Ozkan M, Ozkan CS (2012) Non-invasive high-throughput metrology of functionalized graphene sheets. Adv Func Mater 22(21):45194525. https://doi.org/10.1002/adfm.201200434

Ghosh A (2017) Electronic structure of corrole derivatives: insights from molecular structures, spectroscopy, electrochemistry, and quantum chemical calculations. Chem Rev 117(4):3798-3881. https://doi.org/10.1021/acs.chemrev.6b00590

Gray V, Xia P, Huang Z, Moses E, Fast A, Fishman DA, Vullev VI, Abrahamsson M, Moth-Poulsen K, Lee Tang M (2017) $\mathrm{CdS} / \mathrm{ZnS}$ core-shell nanocrystal photosensitizers for visible to UV upconversion. Chem Sci 8(8):5488-5496. https://doi. org $/ 10.1039 / \mathrm{c} 7 \mathrm{sc} 01610 \mathrm{~g}$
Gross Z, Galili N, Saltsman I (1999) The first direct synthesis of corroles from pyrrole. Angew Chem Int Ed 38(10):14271429. https://doi.org/10.1002/(sici)1521-3773(19990 517)38:10\%3c1427::aid-anie1427\%3e3.0.co;2-1

Gryko DT (2002) Recent advances in the synthesis of corroles and core-modified corroles. Eur J Org Chem 2002(11):1735-1743

Gryko DT, Jadach K (2001) A simple and versatile one-pot synthesis of meso-substituted trans-A(2)B-corroles. J Org Chem 66(12):4267-4275. https://doi.org/10.1021/jo010146w

Guo S, Bao D, Upadhyayula S, Wang W, Guvenc AB, Kyle JR, Hosseinibay H, Bozhilov KN, Vullev VI, Ozkan CS, Ozkan M (2013) Photoinduced electron transfer between pyridine coated cadmium selenide quantum dots and single sheet graphene. Adv Func Mater 23(41):5199-5211. https://doi.org/10.1002/ adfm.201203652

Gupta S, Chatni MR, Rao ALN, Vullev VI, Wang LV, Anvari B (2013) Virus-mimicking nano-constructs as a contrast agent for near infrared photoacoustic imaging. Nanoscale 5(5):1772-1776. https ://doi.org/10.1039/c3nr34124k

Jimenez HR, Julve M, Faus J (1991) A solution study of the protonation and deprotonation equilibria of 5,10,15,20-tetra(para-sulphonatophenyl)porphyrin — stability-constants of its magnesium(Ii), copper(Ii) and zinc(Ii) complexes. J Chem Soc Dalton. https://doi. org/10.1039/dt9910001945

Johnson AW, Kay IT (1961) Synthesis of derivatives of corroleamendment. In: Proceedings of the Chemical Society of London (MAY):168-\&

Johnson AW, Kay IT (1964) Pentadehydrocorrin (corrole) ring system. In: Proceedings of the Chemical Society of London (MAR):89-\&

Johnson AW, Kay IT (1965) Corroles. I. Synthesis. J Chem Soc. https ://doi.org/10.1039/jr9650001620

Johnson AW, Price R (1960a) Synthesis of derivatives of corrole (pentadehydrocorrin). J Chem Soc. https://doi.org/10.1039/jr96000016 49

Johnson AW, Price R (1960b) The synthesis of derivatives of corrole (pentadehydrocorrin). J Chem Soc (APR). https://doi.org/10.1039/ jr9600001649

Jones G II, Lu LN, Vullev V, Gosztola D, Greenfield S, Wasielewski M (1995) Photoactive peptides. 6. Photoinduced electron transfer for pyrenesulfonamide conjugates of tryptophan-containing peptides. Mitigation of fluoroprobe behavior in N-terminal labeling experiments. Bioorg Med Chem Lett 5(20):2385-2390

Jung B, Vullev VI, Anvari B (2014) Revisiting indocyanine green: effects of serum and physiological temperature on absorption and fluorescence characteristics. IEEE J Select Topics Quant Electron 20(2):7000409/7000401-7000409/7000409. https://doi. org/10.1109/jstqe.2013.2278674

Kasha M (1950) Characterization of electronic transitions in complex molecules. Discuss Faraday Soc 9:14-19. https://doi.org/10.1039/ df9500900014

Kruk M, Ngo TH, Verstappen P, Starukhin A, Hofkens J, Dehaen W, Maes W (2012) Unraveling the fluorescence features of individual corrole NH tautomers. J Phys Chem A 116(44):10695-10703. https://doi.org/10.1021/jp305326x

Krzeszewski M, Espinoza EM, Cervinka C, Derr JB, Clark JA, Borchardt D, Beran GJO, Gryko DT, Vullev VI (2018) Dipole effects on electron transfer are enormous. Angew Chem Int Ed 57(38):12365-12369. https://doi.org/10.1002/anie.201802637

Lu H, Bao D, Penchev M, Ghazinejad M, Vullev VI, Ozkan CS, Ozkan M (2010) Pyridine-coated lead sulfide quantum dots for polymer hybrid photovoltaic devices. Adv Sci Lett 3(2):101-109

Mahammed A, Gross Z (2006) Iron and manganese corroles are potent catalysts for the decomposition of peroxynitrite. Angew Chem Int Ed 45(39):6544-6547. https://doi.org/10.1002/anie.200601399 
Mahammed A, Weaver JJ, Gray HB, Abdelas M, Gross Z (2003) How acidic are corroles and why? Tetrahedron Lett 44(10):2077-2079. https://doi.org/10.1016/S0040-4039(03)00174-6

Orlowski R, Vakuliuk O, Gullo MP, Danylyuk O, Ventura B, Koszarna B, Tarnowska A, Jaworska N, Barbieri A, Gryko DT (2015) Selfassembling corroles. Chem Commun 51(39):8284-8287. https:// doi.org/10.1039/c5cc01306b

Orlowski R, Gryko D, Gryko DT (2017a) Synthesis of corroles and their heteroanalogs. Chem Rev 117(4):3102-3137. https://doi. org/10.1021/acs.chemrev.6b00434

Orlowski R, Tasior M, Staszewska-Krajewska O, Dobrzycki L, Schilf W, Ventura B, Cyranski MK, Gryko DT (2017b) Hydrogen bonds involving cavity $\mathrm{NH}$ protons drives supramolecular oligomerization of amido-corroles. Chemistry 23(42):10195-10204. https:// doi.org/10.1002/chem.201701674

Paolesse R, Nardis S, Sagone F, Khoury RG (2001) Synthesis and functionalization of meso-aryl-substituted corroles. J Org Chem 66(2):550-556. https://doi.org/10.1021/jo005661t

Pomarico G, Monti D, Bischetti M, Savoldelli A, Fronczek FR, Smith KM, Genovese D, Prodi L, Paolesse R (2018) Silicon(IV) corroles. Chemistry 24(33):8438-8446. https://doi.org/10.1002/ chem. 201801246

Purc A, Espinoza EM, Nazir R, Romero JJ, Skonieczny K, Jeżewski A, Larsen JM, Gryko DT, Vullev VI (2016) Gating that suppresses charge recombination-the role of mono- $N$-arylated diketopyrrolopyrrole. J Am Chem Soc 138(39):12826-12832. https://doi. org/10.1021/jacs.6b04974

Rabinovich E, Goldberg I, Gross Z (2011) Gold(I) and gold(III) corroles. Chemistry 17(44):12294-12301. https://doi.org/10.1002/ chem. 201102348

Shen J, Ou ZP, Shao JG, Galezowski M, Gryko DT, Kadish KM (2007) Free-base corroles: determination of deprotonation constants in non-aqueous media. J Porphyr Phthalocyanines 11(3-4):269-276. https://doi.org/10.1142/S1088424607000321

Swider P, Nowak-Krol A, Voloshchuk R, Lewtak JP, Gryko DT, Danikiewicz W (2010) Mass spectrometry studies on meso-substituted corroles and their photochemical decomposition products. J Mass Spectrom 45(12):1443-1451. https://doi.org/10.1002/jms. 1860

Szymanski S, Paluch P, Gryko DT, Nowak-Krol A, Bocian W, Sitkowski J, Koszarna B, Sniechowska J, Potrzebowski MJ, Kozerski L (2014) Insights into the tautomerism in meso-substituted corroles: a variable-temperature H-1, C-13, N-15, and F-19 NMR spectroscopy study. Chemistry 20(6):1720-1730. https://doi. org/10.1002/chem.201303406

Tasior M, Gryko DT, Shen J, Kadish KM, Becherer T, Langhals H, Ventura B, Flamigni L (2008) Energy- and electron-transfer processes in corrole-perylenebisimide-triphenylamine array. J Phys Chem C 112(49):19699-19709. https://doi.org/10.1021/jp806 5635

Teo RD, Hwang JY, Termini J, Gross Z, Gray HB (2017) Fighting cancer with corroles. Chem Rev 117(4):2711-2729. https://doi. org/10.1021/acs.chemrev.6b00400

Thomas KE, Conradie J, Beavers CM, Ghosh A (2020) Free-base porphyrins with localized $\mathrm{NH}$ protons. Can substituents alone stabilize the elusive cis tautomer? Org Biomol Chem 18(15):28612865. https://doi.org/10.1039/d0ob00452a

Upadhyayula S, Nunez V, Espinoza EM, Larsen JM, Bao D, Shi D, Mac JT, Anvari B, Vullev VI (2015) Photoinduced dynamics of a cyanine dye: parallel pathways of non-radiative deactivation involving multiple excited-state twisted transients. Chem Sci 6:2237-2251. https://doi.org/10.1039/c4sc02881c

Ventura B, Degli Esposti A, Koszarna B, Gryko DT, Flamigni L (2005) Photophysical characterization of free-base corroles, promising chromophores for light energy conversion and singlet oxygen generation. New J Chem 29(12):1559-1566. https://doi.org/10.1039/ b507979a

Vullev VI (2011) From biomimesis to bioinspiration: what's the benefit for solar energy conversion applications? J Phys Chem Lett 2(5):503-508

Wan J, Ferreira A, Xia W, Chow CH, Takechi K, Kamat PV, Jones G, Vullev VI (2008) Solvent dependence of the charge-transfer properties of a quaterthiophene-anthraquinone dyad. J Photochem Photobiol A 197(2-3):364-374

Zugazagoitia JS, Almora-Diaz CX, Peon J (2008) Ultrafast intersystem crossing in 1-nitronaphthalene. An experimental and computational study. J Phys Chem A 112(3):358-365. https://doi. org/10.1021/jp074809a

Publisher's Note Springer Nature remains neutral with regard to jurisdictional claims in published maps and institutional affiliations. 